26(2), 335-347

\title{
Empirical Mode Decomposition using the Second Derivative
}

\author{
Min-Su Park ${ }^{a} \cdot$ Donghoh $\mathrm{Kim}^{b} \cdot$ Hee-Seok $\mathrm{Oh}^{a, 1}$ \\ ${ }^{a}$ Department of Statistics, Seoul National University \\ ${ }^{b}$ Department of Applied Mathematics, Sejong University
}

(Received February 25, 2013; Revised March 29, 2013; Accepted April 2, 2013)

\begin{abstract}
There are various types of real world signals. For example, an electrocardiogram(ECG) represents myocardium activities (contraction and relaxation) according to the beating of the heart. ECG can be expressed as the fluctuation of ampere ratings over time. A signal is a composite of various types of signals. An orchestra (which boasts a beautiful melody) consists of a variety of instruments with a unique frequency; subsequently, each sound is combined to form a perfect harmony. Various research on how to to decompose mixed stationary signals have been conducted. In the case of non-stationary signals, there is a limitation to use methodologies for stationary signals. Huang et al. (1998) proposed empirical mode decomposition(EMD) to deal with non-stationarity. EMD provides a data-driven approach to decompose a signal into intrinsic mode functions according to local oscillation through the identification of local extrema. However, due to the repeating process in the construction of envelopes, EMD algorithm is not efficient and not robust to a noise, and its computational complexity tends to increase as the size of a signal grows. In this research, we propose a new method to extract a local oscillation embedded in a signal by utilizing the second derivative.
\end{abstract}

Keywords: Empirical mode decomposition, mean envelope, intrinsic mode functions, frequency, electrocardiogram.

\section{1. 서론}

다양한 주파수를 가진 시그널들이 혼합되어 하나의 시그널 형태로 관찰되는 경우가 흔하다. 우리 주 위에서 쉽게 접할 수 있는 음악을 예로 들어보자. 음악에는 다양한 악기의 소리가 혼합되어 있다. 악기는 그 형태와 재료 및 소리 발생방법에 따라 서로 다른 음색을 가지는데, 각 음색은 소리 파 형(wave form)으로 결정된다. 바이올린은 $164 \sim 1568(\mathrm{~Hz})$, 비올라는 $130 \sim 1174(\mathrm{~Hz})$, 그리고 플룻은 261 2349(Hz)의 음역대를 가진다. 이처럼 서로 다른 소리의 파형들이 모여서 아름다운 음악이 생성된

This work was supported by a grant from the Next-Generation BioGreen 21 Program (No. PJ008068), Rural Development Administration, Republic of Korea and by Basic Science Research Program through the National Research Foundation of Korea (NRF) funded by the Ministry of Education, Science and Technology (2012R1A1A2039968).

${ }^{1}$ Corresponding author: Professor, Department of Statistics, Seoul National University, 1 Gwanak-ro, Gwanak-gu, Seoul 151-747, Korea. E-mail: heeseok@stats.snu.ac.kr 
다. 이러한 음악을 기계장비를 통하여 시그널의 형태로 변환하여 저장하거나 전송할 수 있다. 특정 악 기의 소리만을 추출하거나 기계장비 및 물리적인 이유로 발생한 잡음(error)을 제거하고자 할 경우, 원 시그널을 각 구성요소 별로 식별하거나 분해하는 방법이 필요하다. 이러한 분해방법은 금융 자료의 분 석, 생산과정 공정이상의 식별, 그리고 의료진단 등 현실세계에서 널리 사용되고 있다.

시그널이 정상(stationary)인 경우에는 시계열 모형 (Priestley, 1981)과 다항회귀분석 등을 통해서 분 석이 가능하지만, 비선형(non-linear)이거나 비정상(non-stationary)인 경우 기존의 통계적 분석 방법 으로는 한계를 가지고 있다. Huang 등 (1998)은 시그널이 비정상일 경우에도 사용할 수 있는 자료적 응적인(data-adaptive) 방법론을 제안하였으며, 시그널 속에 내재되어 있는 형태가 서로 다른 내재모 드함수들(intrinsic mode functions)을 추출한다. 기존의 시계열 자료 분석의 경우에는 특정한 모형을 따르거나 정상인 경우에만 사용 가능하였지만, 경험적 모드분해법은 이를 확장하였다는 장점을 가지고 있다. 이러한 장점으로 언어자료 (Liu 등, 2005), 생물자료 (Huang 등, 2002), 지진자료 (Zhang 등, 2003), 기후자료 (Coughlin과 Tung, 2004), 금융자료 (Kim과 Oh, 2009a; Huang 등, 2003), 공학자 료 (Huang과 Shen, 2005), 이미지자료 (Kim 등, 2012b) 등을 분석하기 위하여 사용되어 왔다. 또한 $\mathrm{Kim}$ 과 Oh (2006)와 Kim 등 (2012a)는 예측과 평활 등에 적용하기 위한 방법론을 제안하였다. 경험적 모드분해법을 구현하기 위한 패키지 (Kim과 Oh, 2013; Kim과 Oh, 2009b) EMD가 개발되어 있다.

그러나 경험적 모드분해법은 내재모드함수들을 추출하기 위해 모든 국소 극값(local extrema)을 반복적 으로 식별해야 하므로 계산과정이 복잡하다. 또한 시그널에 잡음이 섞여 있는 경우나 이상값(outlier)이 있는 경우에는 국소적인 자료 패턴을 추출하는 과정이 용이하지 않다. 이러한 알고리듬의 단점을 개선 하기 위한 여러 방안이 제안되어 왔다 (Deering과 Kaiser, 2005; Rilling 등, 2003; Zeng과 He, 2004; $\mathrm{Wu}$ 와 Huang, 2009). 본 연구에서는 경험적 모드분해법에서 사용하는 국소파형 식별 방법을 이차미분 을 활용한 방법으로 대체하여 다양한 파형으로 구성되어 있는 시그널을 효과적이고 효율적으로 분해하 는 방법론을 제시하고자 한다.

본 논문의 전개 내용은 다음과 같다. 2 절에서 경험적 모드분해법에 대해 간략히 기술하고, 3 절에서는 이 차미분을 이용하여 시그널을 분해하는 새로운 분해법을 제안하고자 한다. 4 절과 5 절에서는 모의실험과 실제 자료 분석을 수행하여 제안한 방법의 실효성에 대해서 검토하고자 한다.

\section{2. 경험적 모드분해법}

다음과 같이 시간 $t$ 에 따른 사인파모양 함수(sinusoidal function)을 고려하자.

$$
s(t)=A(t) \cos (\omega(t)),
$$

여기서 $A(t)$ 와 $\omega(t)$ 는 시간에 따라 변하는 진폭(amplitude)과 주파수(frequency)를 의미한다. 위의 사 인파모양 함수는 일정한 행태(behavior)가 반복되며 시간에 따라 진폭과 주파수가 변하여 비정상적 양 상을 표현할 수 있다. 이러한 함수의 특성을 다음과 같이 살펴보자.

특성 1. 반복되는 행태를 어떤 국소 극대값과 그 다음 국소 극대값 사이의 구간에서 살펴보자. 0 을 지나 는 2 개의 지점과 그 사이에 국소 극소값이 존재한다는 사실을 알 수 있다.

특성 2. 국소 극대값들과 국소 극대값들 각각에 대해 보간법(interpolation)으로 산출한 함수들을 상위 막(upper envelope)과 하위막(lower envelope)이라고 하자. 위의 사인파모양 함수는 대체로 상위막과 하위막 사이에 존재하고, 상위막과 하위막의 평균인 평균막(mean envelope)에 대해 국소적으로 대칭적이다. 
Huang 등 (1998)은 이러한 특성을 다음의 2 가지 성질로 기술하고, 임의의 시그널이 이 성질을 만족할 경우 내재모드함수(intrinsic mode functions)라 하였다. 0 을 지나는 지점을 영통과점(zero-crossing)이 라 하자.

- 국소 극값의 개수와 영통과점의 개수의 차이는 한 개 이하이다.

- 평균막의 국소 평균은 0 이다.

사인파모양 함수 (2.1)의 경우 하나의 주파수 함수를 고려하고 있으나, 다양한 형태의 비정상성 시그널 은 여러 개의 주파수 함수들이 혼합되어 있다고 할 수 있다. Huang 등 (1998)은 내재모드함수의 특성 을 역으로 이용하여 임의의 시그널을 주파수 수준(level)순으로 분해하는 경험적 모드분해법을 고안하였 다. 경험적 모드분해법의 과정을 알고리듬과 그림으로 묘사하면 다음과 같다.

1. 분해 대상의 시그널을 $s$ 라고 하자.

2. 주어진 시그널을 가장 빠른 주기를 가지는 내재모드함수와 잔여시그널(residue)로 분해한다.

2.1. 주어진 시그널의 국소 극대값과 국소 극소값을 모두 식별한다 (Figure 2.1. step 1).

2.2. 국소 극대값에 대해 보간법(interpolation)으로 상위막을 생성한다. 마찬가지로, 동일한 과정을 통해서 국소 극소값으로 하위막을 생성한다 (Figure 2.1. step 2).

2.3. 상위막과 하위막의 평균인 평균막 $m(t)$ 을 계산한다 (Figure 2.1. step 3).

2.4. 시그널(첫 번째 내재모드함수에 대해선 $r_{0}(t)=s(t)$ )과 평균막의 차이로 고주파 성질을 가지는 $d(t)=r_{0}(t)-m(t)$ 를 생성한다 (Figure 2.1. step 4).

2.5. 과정 2.4에서 구한 $d(t)$ 가 내재모드함수의 성질을 만족하면 $d(t)$ 를 내재모드함수 $\mathrm{imf}_{1}$ 로 간주하 고 계산과정을 멈춘다. $d(t)$ 가 내재모드함수의 성질을 만족하지 않을 경우, $d(t)$ 에 대하여 과정 $2.1 \sim 2.4$ 를 반복한다.

3. 시그널 $s$ 를 내재모드함수 $\mathrm{imf}_{1}$ 와 잔여시그널 $r=s-\mathrm{imf}_{1}$ 로 분해한다.

4. 잔여시그널 $r$ 이 주기를 가지고 있을 경우, 잔여시그널 $r$ 을 새로운 시그널 $s$ 로 간주하여 과정 $1 \sim 3$ 을 반복한다.

5. 최종적으로 $k$ 개의 내재모드함수 $\mathrm{imf}_{1}, \ldots, \mathrm{imf}_{k}$ 와 잔여시그널 $r$ 을 산출한다.

$$
s(t)=\operatorname{imf}_{1}(t)+\cdots+\operatorname{imf}_{k}(t)+r(t) .
$$

과정 2 와 같이 반복되는 과정을 체거름과정(sifiting)이라고 부르며, 체거름과정을 통하여 시그널에서 고 주파(high frequencies) 성질을 가진 함수부터 저주파(low frequencies) 성질을 가진 함수를 순차적으로 추출할 수 있다.

\section{3. 이차 미분을 이용한 내재모드함수의 산출}

체거름과정은 2 절에서 설명한 사인파모양 함수의 특성 1 과 2 를 이용한 알고리듬이며 경험적 모드분해 법의 핵심이라고 할 수 있다. 체거름과정은 주어진 시그널이 대칭적일 수 있는 평균막을 산출하여, 시그 널에서 반복적으로 제거하는 과정이다. 평균막을 산출하기 위해 국소 극대값과 국소 극소값을 식별하여 상위막과 하위막을 각각 계산하는 과정을 반복하므로, 시그널의 자료수가 커짐에 따라 계산량이 많아지 게 된다. 또한 잡음(error)에 의해 자료가 오염되어 국소 극값에 변동이 있을 경우 국소적인 파동을 추 정하기 어려운 점이 있다. 한편 2 절에서 설명한 사인파모양 함수의 특성 2 를 다음과 같이 다른 측면에 서 해석할 수 있다. 

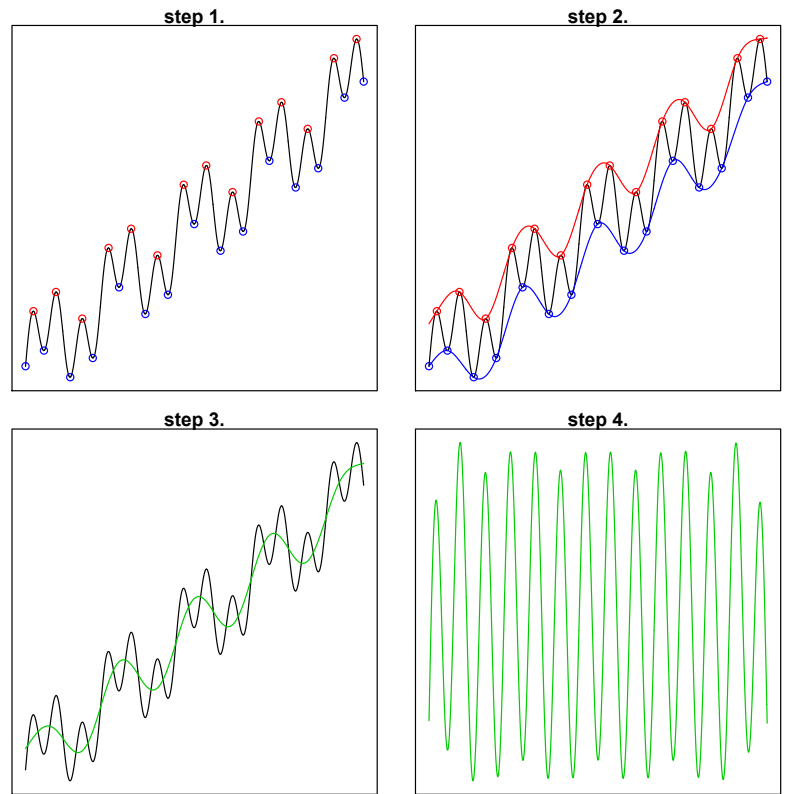

Figure 2.1. The sifting process of EMD

특성 2. 변곡점(inflection point) 중 이차 미분의 부호가 변곡점 전후로 변하는 점들을 식별한 후, 보 간법(interpolation)으로 산출한 함수를 평균막(mean envelope)이라 하자. 사인파모양 함수는 평균막에 대해 국소적으로 대칭적이다.

이러한 특성을 이용할 경우 체거름과정 중 국소 극값을 식별하거나 상위막과 하위막을 별도로 계산하는 과정을 거치지 않고 평균막을 산출할 수 있다. 시그널 $s$ 가 연속적으로 2 번 미분가능 하다고 가정하면, $h>0$ 에 대하여 근사적으로 다음을 만족한다.

$$
s^{\prime \prime}(t) \approx \frac{s(t-h)-2 s(t)+s(t+h)}{h^{2}} .
$$

등간격 $h$ 의 시점 $\left\{t_{i}\right\}_{i=1}^{n}$ 에서 시그널 $\left\{s\left(t_{i}\right)\right\}_{i=1}^{n}$ 을 관찰한 경우 $t_{i}$ 시점의 이차 미분값을 다음과 같이 근 사적으로 산출할 수 있다.

$$
s^{\prime \prime}\left(t_{i}\right) \approx \frac{s\left(t_{i-1}\right)-2 s\left(t_{i}\right)+s\left(t_{i+1}\right)}{h^{2}} .
$$

본 연구에서는 근사적인 이차 미분 (3.1)을 활용한 체거름과정을 적용하여 국소적인 파동을 식별하고 추 정하는 새로운 방법론을 제시하고자 한다. 이차 미분을 이용한 체거름과정과 경험적 모드분해법을 각각 수정 체거름과정(modified sifting), 수정 경험적 모드분해법(modified EMD)이라 명명하자. 수정 경험 적 모드분해법은 2 절에 설명한 알고리듬의 과정 2 의 체거름과정을 다음과 같이 수정 체거름과정으로 대 체한다는 점을 제외하고는 기존의 경험적 모드분해법과 동일하다.

2. 주어진 시그널을 가장 빠른 주기를 가지는 내재모드함수와 잔여시그널(residue)으로 분해한다.

2.1. 수식 (3.1)에 의해 이차 미분값을 근사적으로 산출하고, 이차 미분값의 부호가 변하는 2 개의 점 들을 식별한다. 

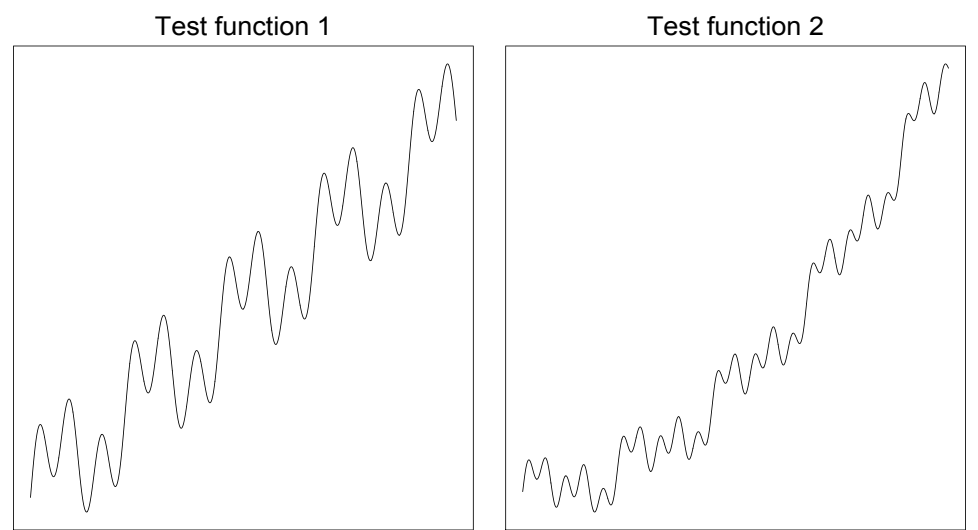

Figure 4.1. Test function $f_{1}(t)$ and $f_{2}(t)$

2.2. 두 점들 사이에서 이차 미분함수가 선형이라고 가정하고 $s^{\prime \prime}$ 이 0 이 되는 $t_{*}$ 를 도출하고, $t_{*}$ 를 구 한 방법과 동일하게 주어진 시그널을 통해서 $s\left(t_{*}\right)$ 값도 구한다.

2.3. 과정 2.2 에서 산출한 모든 $t_{*}$ 와 $s\left(t_{*}\right)$ 값에 대하여 보간법(interpolation) 중 하나인 삼차 스플라 인(cubic spline)을 사용하여 평균막 $m(t)$ 을 계산한다.

2.4. 시그널과 평균막의 차이로 고주파 성질을 가지는 $d(t)=r_{0}(t)-m(t)$ 를 생성한다.

2.5. 과정 2.4에서 구한 $d(t)$ 가 내재모드함수의 성질을 만족하면 $d(t)$ 를 내재모드함수 $\mathrm{imf}_{1}$ 로 간주하 고 계산과정을 멈춘다. $d(t)$ 가 내재모드함수의 성질을 만족하지 않을 경우, $d(t)$ 에 대하여 과정 $2.1 \sim 2.4$ 를 반복한다.

\section{4. 사례연구}

사례를 통하여 제안한 체거름과정의 실효성을 살펴보고자 한다. 다음의 가상적인 시그널 $f_{1}(t)$ 와 $f_{2}(t)$ 를 고려해 보자. Figure 4.1은 각 가상 시그널에 대해 묘사하고 있다.

$$
\begin{aligned}
& f_{1}(t)=0.5+1 \times t+\sin (\pi t)+\sin (3 \pi t), \\
& f_{2}(t)=0.5+\frac{t^{2}}{3}+\sin (\pi t)+\sin (2 \pi t)+\sin (5 \pi t) .
\end{aligned}
$$

가상적인 시그널은 서로 다른 주파수를 가진 사인함수들과 선형 또는 이차 함수의 추세가 섞여 있는 형태이며, 이를 경험적 모드분해법과 제안한 수정 경험적 모드분해법을 사용하여 결과를 비교하였다. Figure 4.2 와 Figure 4.3 에서 왼쪽 열은 제안한 방법의 분해결과이며, 오른쪽 열은 기존의 경험적 모드 분해법으로 분해한 결과이다. 검정색 실선은 각각의 방법론을 사용하여 얻은 내재모드함수와 잔여시그 널이고, 붉은색 점선은 각 사인함수와 추세함수를 나타낸다. 두 방법론 모두 사인함수에 근사한 내재모 드함수를 산출하지만 경계(boundary) 부근에서는 제안한 방법이 기존 경험적 모드분해법보다 더 좋은 효율성을 보인다. 가상 시그널 $f_{1}(t)$ 의 평균제곱오차(MSE) 값을 비교하면 첫 번째 내재모드함수에 대 해 제안한 방법론이 0.000053 로 기존 경험적 모드분해법 0.056 보다 적은 수치이며, 두 번째 내재모드 함수도 0.0002 와 0.015 로 수정 경험적 모드분해법이 좋은 결과를 가져온다. $f_{2}(t)$ 시그널에서 세 개의 내재모드함수에 대한 $\mathrm{MSE}$ 값은 제안한 방법론이 각각 $0.0002 / 0.0053 / 0.02$ 으로 경험적 모드분해법의 $0.0083 / 0.016 / 0.058$ 보다 좋은 효율성을 갖는 것을 알 수 있다. 

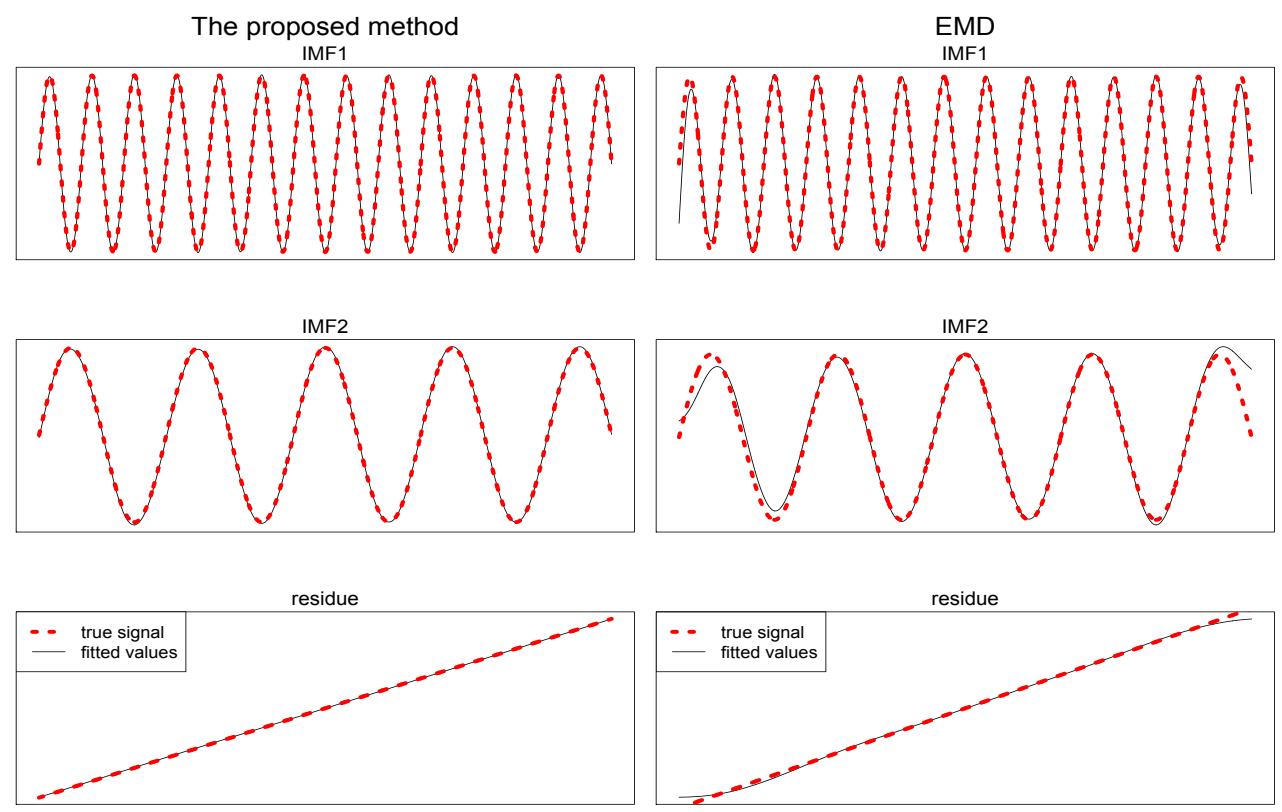

Figure 4.2. Decomposition results by EMD and modified EMD for $f_{1}(t)$
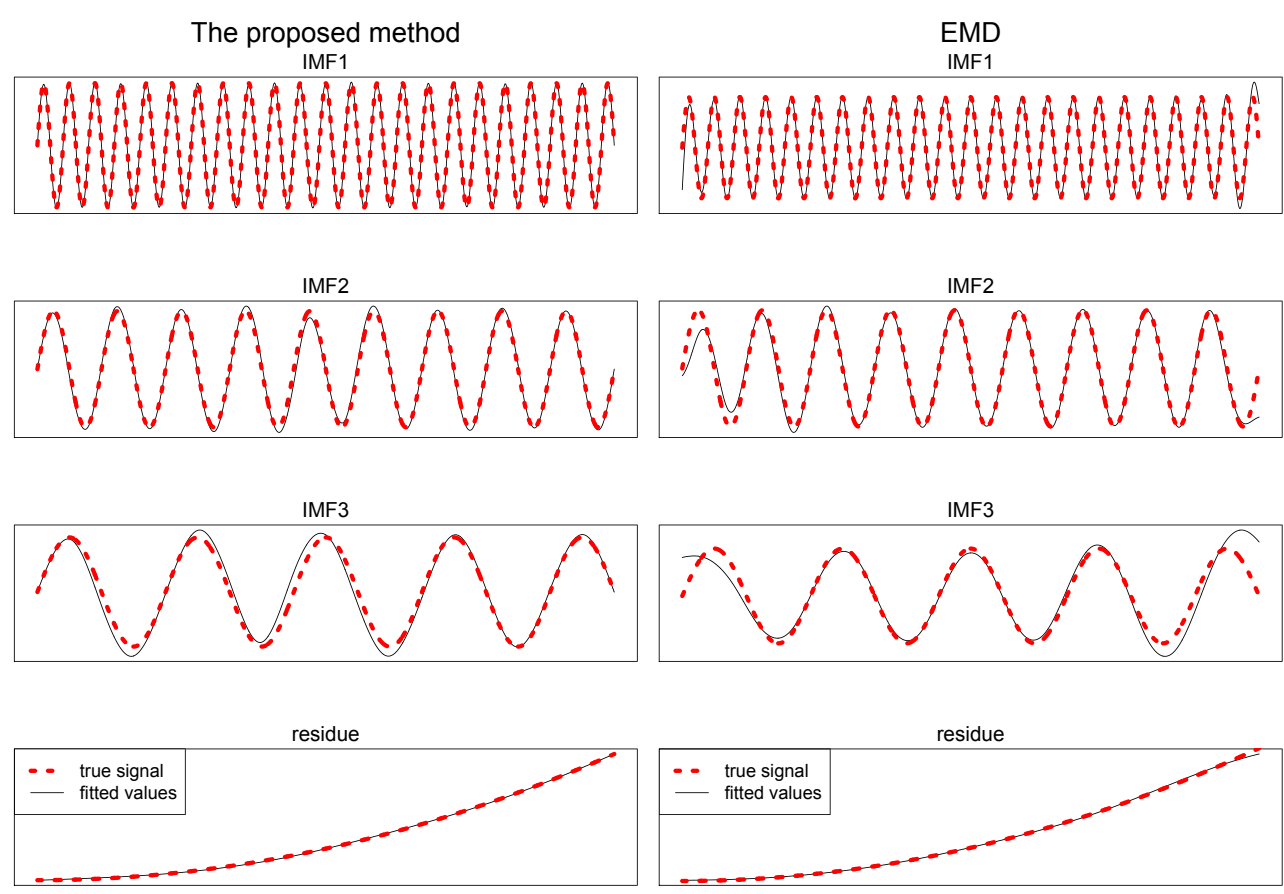

Figure 4.3. Decomposition results by EMD and modified EMD for $f_{2}(t)$ 
The proposed method signal

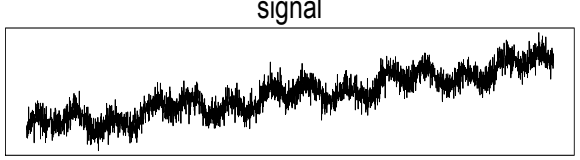

IMF1

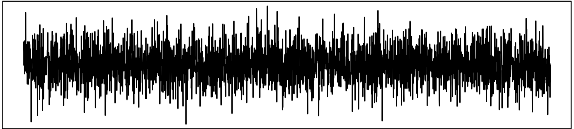

remaining signal

- true signal
remaining signal

EMD

signal

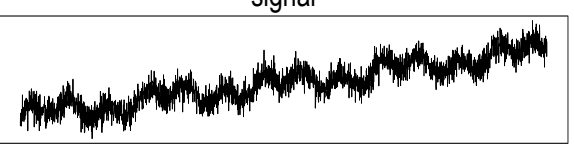

IMF1

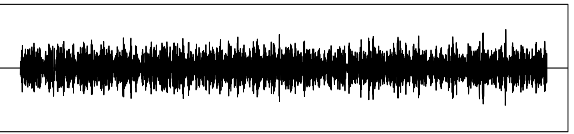

IMF2

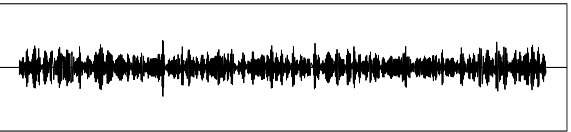

IMF3

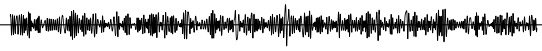

remaining signal

- - true signal
remaining signal

Figure 4.4. Decomposition results by EMD and modified EMD for $f_{1}(t)$ contaminated with Gaussian noise

시그널이 잡음에 의해 오염되어 있는 경우 제안한 방법이 효과적으로 잡음을 분해할 수 있는지 살펴보았 다. 가상적인 시그널 $f_{1}$ 이 평균이 0 , 분산이 1 인 가우시안 잡음(Gaussian noise)에 의해 오염된 경우를 고려하여 보자. 이 경우 시그널대잡음 비(signal-to-noise ratio)는 8.3이며, 자료는 3000 개를 사용하였 다. Figure 4.4와 같이 제안한 방법은 첫 번째 내재모드함수가 잡음을 효과적으로 추출하는 반면, 기존 의 경험적 모드분해법은 세 개의 내재모드함수에 잡음이 혼재되어 있다는 것을 알 수 있다. 수정 경험적 모드분해법은 잡음에 강건하다는 것을 알 수 있다.

일차원 시그널에 대한 수정 경험적 모드분해법을 확장하여 이차원 이미지에 적용할 수 있다. 즉, 각 차 원에 대해 일차원에서의 이차 미분을 사용하여 이차원에 적용 가능한 방법으로 확장할 수 있다. 다음과 같은 서로 다른 주파수를 가진 가상적인 이미지(image)를 고려해 보자.

$$
f(t, s)=\sin (2 \pi t) \sin (2 \pi s)+\sin (5 \pi t) \sin (5 \pi s) .
$$

Figure 4.5와 같이 수정 경험적 모드분해법으로 도출한 이차원 내재모드함수가 기존 방법으로 산출한 이차원 내재모드함수보다 각 주파수의 이미지와 유사하다는 것으로 알 수 있다. 


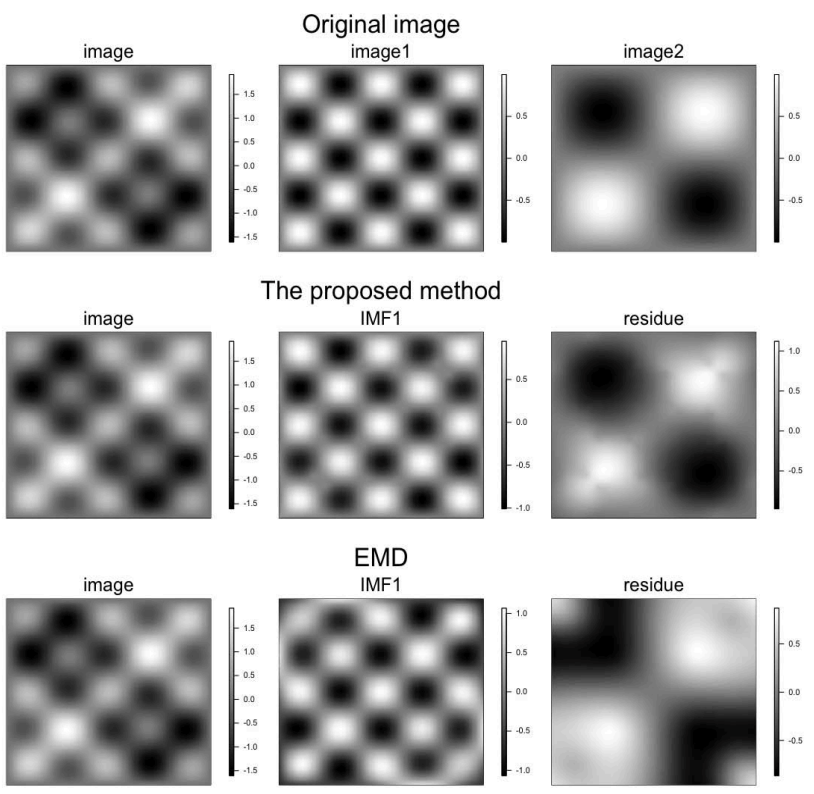

Figure 4.5. Decomposition results by EMD and modified EMD for the test image $f(t, s)$

\section{5. 실제 자료의 분석}

본 절에서는 3 절에서 제안한 방법론을 이용하여 심전도 자료를 분해하고 그 결과를 해석하고자 한다. 심전도 자료는 순수한 심장박동만으로 이루어지지 않고, 측정 기구로부터의 잡음, 호흡에 의한 시그널 등이 혼재되어 있다. 호흡 주기에 따른 공기의 유출입이 심전도에 영향을 미치게 되며, 이러한 현상을 심전도 유도 호흡(ECG-derived respiration; EDR)이라고 한다. 심전도 자료로부터 심전도 유도 호흡 신호를 분리하는 방법론은 다양하게 연구되고 있다 (Yi 등, 2006; Blanco-Velasco 등, 2008; Campolo 등, 2011). 정확한 판독을 위해서는 심전도 자료를 서로 다른 주파수를 가진 파형으로 분리하여야 하고, 분리한 파형을 사용하여 신체 중 특정 부분의 이상을 진단하게 된다.

본 연구에 활용된 심전도 자료는 66 일 된 아기의 심전도 자료로 R 패키지 wavethresh (Nason, 2012)에 있는 BabyECG 자료이며, 16 초 간격으로 심전도를 측정하여 총 2048 개 자료로 구성되어 있다. 제안한 방법을 사용하여 심전도에서 유도호흡 신호를 분리하고자 한다.

심전도 시그널은 주기가 상대적으로 긴 파형을 갖는 시그널과 국소적으로 파동이 심한 시그널로 구성되 어 있다. 이 중 호흡으로 인한 파형은 다음과 같이 설명될 수 있다. 들숨에서는 공기가 유입하므로 흉 곽의 임피던스(impedance)는 증가하게 되며 이로 인해 피부전극으로 측정되는 심전도의 크기는 작아진 다. Figure 5.1의 맨 위 그림에서와 같이 시그널이 소폭으로 내려가는 현상은 들숨으로 인한 현상이며, 시그널이 증가하는 부분은 이와 반대로 적용되는 날숨으로 인한 현상이다. 심전도 유도 호흡은 심전도 의 진폭이 호흡 주기에 따라 변한다는 것을 이용하여 호흡과 관련된 시그널을 유도하면 되고, 이를 위해 제안한 방법으로 호흡에 따른 물리적 영향과 심장박동의 신호를 구분해 내고자 한다.

제안한 방법으로 심전도 자료를 분해하면 Figure 5.1 과 같이 8 개의 내재모드 함수를 산출하며, 주파수 의 주기가 짧은 신호와 전체적인 형태를 보여주는 신호들로 구성되어 있다. Figure 5.1의 첫 번째 내재 모드함수는 심장박동이라고 추정되며, 내재모드함수 2 에서 5 까지는 주기가 상대적으로 긴 호흡과 관련 
signal

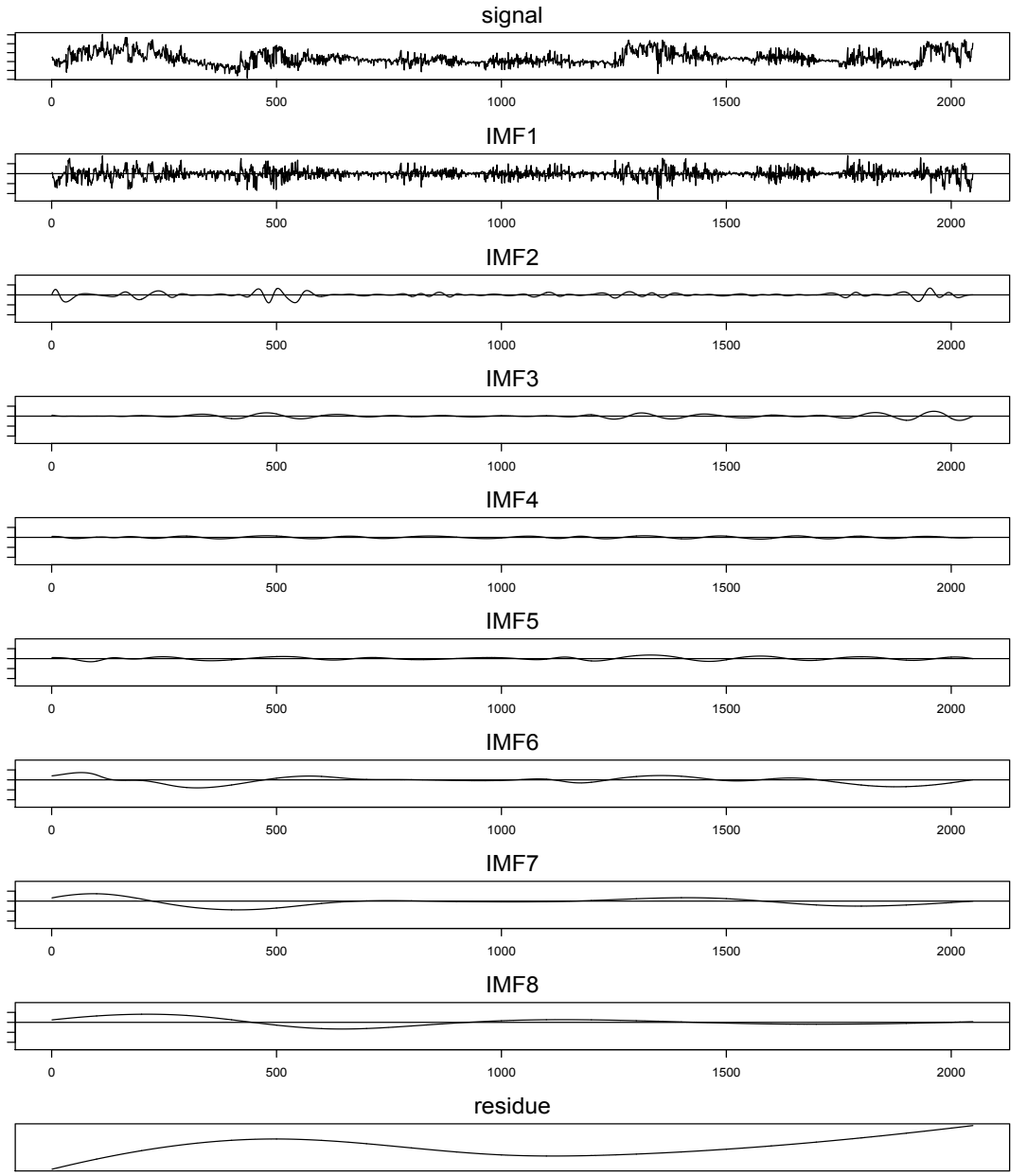

Figure 5.1. Results of the ECG data using modified EMD

된 신호로 추정된다. 나머지 6 에서 8 까지는 주기가 긴 심전도 파형을 나타낸다.

Figure 5.2에 심장박동이라고 추정되는 첫 번째 내재모드함수 신호(두 번째 그림)와 호흡으로 인한 신호 로 추정되는 내재모드함수 $2,3,4,5$ 를 합하여(세 번째 그림) 표현하였다. 호흡신호는 내재모드함수 중 에서 주파수의 주기가 지극히 길거나 짧은 시그널들을 제외한 함수들을 선택하여 합한 결과이다.

Figure 5.3은 심전도 자료에 평활법(smoothing splines)을 적용하여 잔차부분(두 번째 그림)과 평활 부분(세 번째 그림)으로 분해한 결과를 나타낸다. 평활계수(smoothing parameter)는 일반화교차타당 성(generalized cross validation)에 기반하여 산출하였다. 평활한 시그널은 Figure 5.2의 마지막 그림 과 비슷한 형태를 지니고 있지만 주기와 진폭에 차이가 있다. 주기가 짧은 파동을 더욱 많이 내포하고 있는데, 이는 순수한 심장박동 신호를 모두 분리하지 못함을 의미한다. 또한 호흡신호라고 추정하기에 는 진폭의 값이 크므로, 호흡신호와는 다른 성격의 신호가 혼재되어 있음을 알 수 있다. 실제 자료 분석 결과, 평활법보다 제안된 방법으로 심전도 유도 호흡을 추출하는 것이 효과적임을 알 수 있다. 

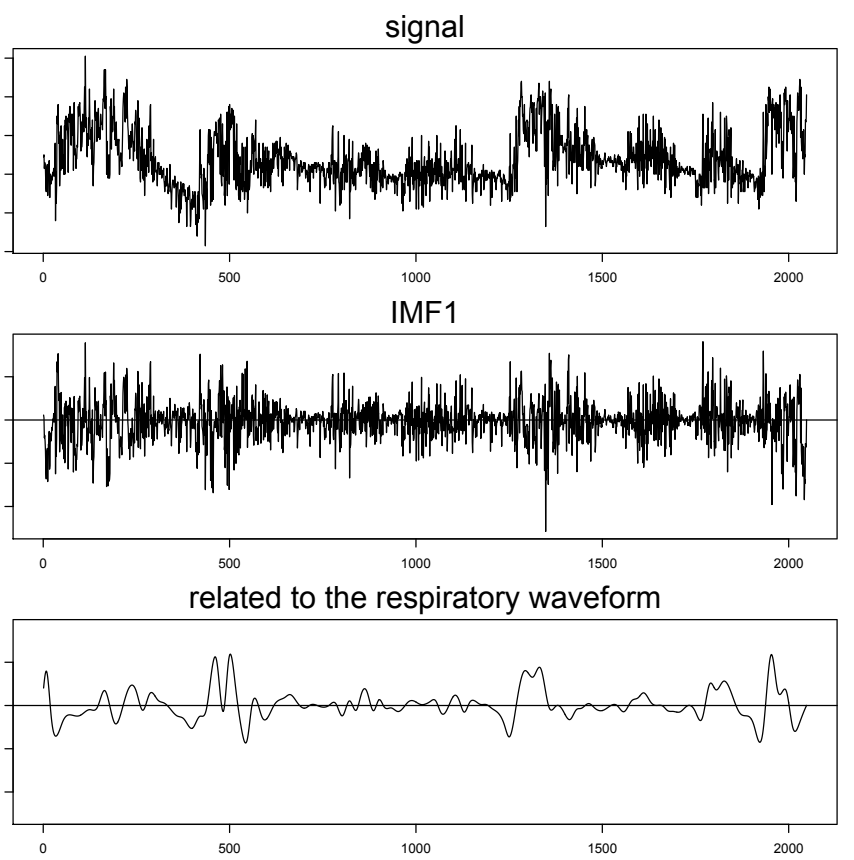

Figure 5.2. Reconstitution of the ECG data related to modified EMD
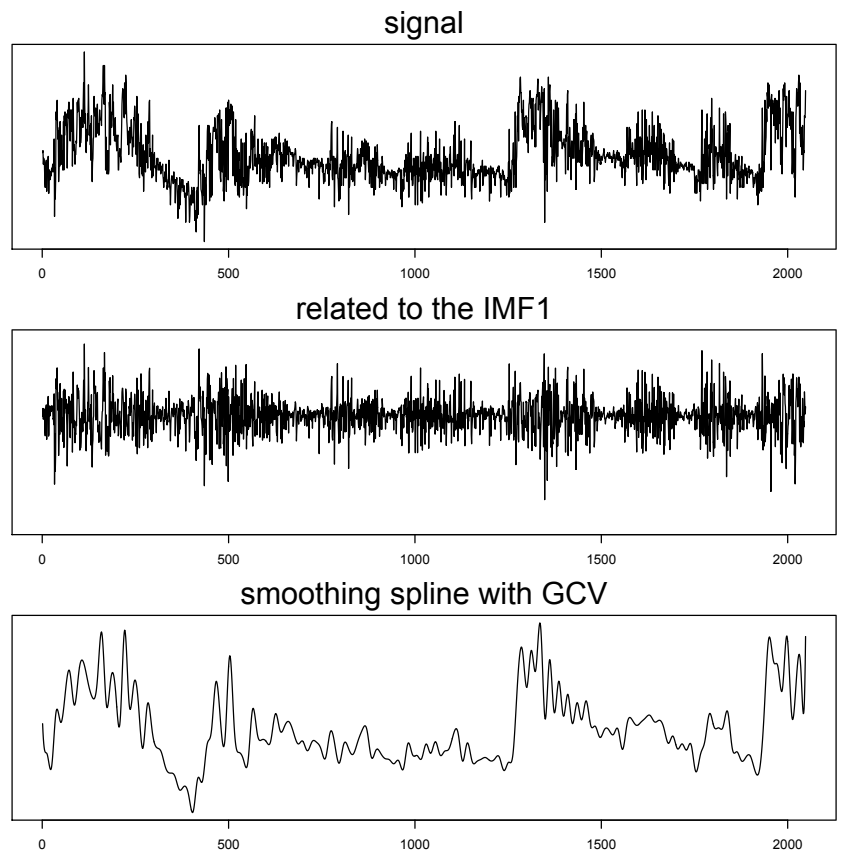

Figure 5.3. Results of smoothing splines for the ECG data 


\section{6. 토의 및 결론}

기존의 경험적 모드분해법은 계산량이 많다는 점과 잡음에 강건하지 못한다는 단점을 가지고 있다. 본 연구에서는 국소 극대값으로부터 상위막과 하위막을 계산하는 알고리듬 부분을 개선하기 위하여 자료로 부터 평균막을 직접 추출할 수 있는 방법론을 제시하였다. 시그널의 상대적인 증가 또는 감소의 변화를 감지하는 이차 미분을 활용한 알고리듬을 제안하였으며, 사례연구를 통하여 효율성을 입증하였다. 또한 일차원에서 개발한 방법을 이차원으로 확장하여 이미지 자료 분해에도 적용 가능 하다는 것을 확인하였 다.

제안한 방법으로 실제 자료를 분석하여 의미 있는 결과를 도출하였다. 심전도에서 호흡이 미치는 영향 을 분리하였다. 순수한 심장 박동의 파형과 호흡으로 인하여 발생하는 저주파 형태의 파동은 서로 다른 주파수 형태를 가지게 되며, 이를 분류하여 특정 질병이 호흡 불안에서 기인하는지 또는 심장의 기능저 하에 기인하는지를 판독할 수 있는 분해 방법론을 제시하였다.

추후 경계문제(boundary problem), 이상값의 처리, 헤시안 행렬(Hessian matrix)을 이용한 이차원 이 미지 자료의 분해 등에 대한 연구를 진행하고자 한다.

\section{References}

Blanco-Velasco, M., Weng, B. and Barner, K. E. (2008). ECG signal denoising and baseline wander correction based on the empirical mode decomposition, Computers in Biology and Medicine, 38, 1-13.

Campolo, M., Labate, D., La Foresta, F., Morabito, F. C., Lay-Ekuakille, A. and Vergallo, P. (2011). ECGderived respiratory signal using empirical mode decomposition, In Proceedings of the IEEE International Symposium on Medical Measurements and Applications (MeMeA '11), article 5966727.

Coughlin, K. T. and Tung, K.-K. (2004). 11-year solar cycle in the stratosphere extracted by the empirical mode decomposition method, Advances in Space Research, 34, 323-329.

Deering, R. and Kaiser, J. F. (2005). The use of a masking signal to improve empirical mode decomposition, Proceedings of the IEEE International Conference on Acoustics, Speech, and Signal Processing, 4, $485-488$.

Huang, N. E. and Shen, S. S. P. (2005). Hilbert-Huang Transform and Its Applications, World Scientific, Singapore.

Huang, N. E., Shen, Z., Long, S. R., Wu, M. L., Shih, H. H., Zheng, Q., Yen, N. C., Tung, C. C. and Liu, H. H. (1998). The empirical mode decomposition and Hilbert spectrum for nonlinear and nonstationary time series analysis, Proceedings of the Royal Society London A, 454, 903-995.

Huang, N. E., Wu, M.-L. C., Qu, W., Long, S. R., Shen, S. S. P. and Zhang, J. E. (2003). Applications of Hilbert-Huang transform to non-stationary financial time series analysis, Applied Stochastic Models in Business and Industry, 19, 245-268.

Huang, W., Sher, Y.-P., Peck, K. and Fung, Y. C. (2002). Matching gene activity with physiological functions, Proceedings of the National Academic of Sciences of the United States of America, 99, 2603-2608.

Kim, D., Kim, K. O. and Oh, H. S. (2012a). Extending the scope of empirical mode decomposition using smoothing, EURASIP Journal on Advances in Signal Processing, 2012:168.

Kim, D. and Oh, H. S. (2006). Hierarchical Smoothing Technique by Empirical Mode Decomposition, The Korean Journal of Applied Statistics, 19, 319-330.

Kim, D. and Oh, H. S. (2009a). A multi-resolution approach to non-stationary financial time series using the Hilbert-Huang transform, The Korean Journal of Applied Statistics, 22, 499-513.

Kim, D. and Oh, H. S. (2009b). EMD: A package for empirical mode decomposition and Hilbert spectrum, The $R$ Journal, 1, 40-46.

Kim, D. and Oh, H. S. (2013). EMD: Empirical mode decomposition and Hilbert spectral analysis, http://cran.r-project.org/web/packages/EMD/index.html

Kim, D., Park, M. and Oh, H. S. (2012b). Bidimensional statistical empirical mode decomposition, IEEE Signal Processing Letters, 19, 191-194. 
Liu, Z.-F., Liao, Z.-P. and Sang, E.-F. (2005). Speech enhancement based on Hilbert-Huang transform, Proceedings of 2005 International Conference on Machine Learning and Cybernetics, 8, 4908-4912.

Nason, G. (2012). wavethresh: Wavelets statistics and transforms, http://cran.r-project.org/web/packages/ wavethresh/index.html

Priestley, M. B. (1981). Spectral Analysis and Time Series Vols. 1 and 2, Academic Press, New York.

Rilling, G., Flandrin, P. and Goncalves, P. (2003). On empirical mode decomposition and its algorithm, IEEE-EURASIP Workshop on Nonlinear Signal and Image Processing, NSIP-03.

$\mathrm{Wu}$, Z. and Huang, N. E. (2009). Ensemble empirical mode decomposition: a noise assisted data analysis method, Advances in Adaptive Data Analysis, 1, 1-49.

Yi, K. H., Park, S. B. and Yoon, H. R. (2006). Real time ECG derived respiratory extraction from heart rate for single lead ECG measurement using conductive textile electrode, The Transactions of the Korean Institute of Electrical Engineers, 55, 335-343.

Zeng, K. and He, M.-X. (2004). A simple boundary process technique for empirical mode decomposition, Proceedings of 2004 IEEE International Geoscience and Remote Sensing Symposium, 6, 4258-4261.

Zhang, R. R., Ma, S., Safak, E. and Hartzell, S. (2003). Hilbert-Huang transform analysis of dynamic and earthquake motion recordings, Journal of Engineering Mechanics, 129, 861-875. 


\title{
이차 미분을 이용한 경험적 모드분해법
}

\author{
박민수 $^{a} \cdot$ 김동호 $^{b} \cdot$ 오희석 ${ }^{a, 1}$ \\ ${ }^{a}$ 서울대학교 통계학과, ${ }^{b}$ 세종대학교 수학통계학부
}

(2013년 2월 25일 접수, 2013년 3월 29일 수정, 2013년 4월 2일 채택)

요 약

다양한 분야에서 시그널(signal) 형태로 자료들이 표현된다. 예를 들면 심전도(electrocardiogram)는 심근에서 발 생하는 활동 전류를 나타내는데, 심장의 박동에 따라 수축과 이완을 반복하는 과정을 시간에 따른 활동 전류량의 변동으로 나타낸다. 현실세계에서 측정하거나 관찰되는 시그널에는 다양한 형태의 시그널들이 혼합되어 있는 경 우가 흔하다. 예를 들어 오케스트라 연주의 아름다운 선율은 고유한 주파수(frequency)를 지닌 악기들의 다양한 소리로 구성되어 있으며, 각기 다른 음조(note)가 하나로 모여 완벽한 하모니를 형성하게 된다. 시그널이 정상 인(stationary) 경우에 혼합된 시그널들을 분해하여 분석하는 방법에 대해 현재까지 다양하게 연구되어 왔다. 자 료가 비정상(non-stationary)일 경우에는 기존의 방법론들을 적용시키기에는 한계가 있다. 비정상성 자료를 다루 기 위해 Huang 등 (1998)은 경험적 모드분해법(empirical mode decomposition)이라는 방법을 제안하였다. 자료 에 내포되어 있는 국소적인 파동(oscillation)을 국소 극값들(local extrema)을 식별하여 자료 적응적으로 추출한다. 경험적 모드분해법은 잡음(error)에 의해 자료가 오염되어 있는 경우에는 국소 극값들을 통하여 국소적인 파동을 추 정하기 어려우며, 자료의 크기가 커짐에 따라 계산량도 크게 늘어나는 단점 등이 있다. 본 연구에서는 이차 미분을 이용하여 국소적인 파동을 식별하고 추정하는 새로운 방법론을 제시하고자 한다.

주요용어: 경험적 모드분해법, 평균막, 내재모드함수, 주파수, 심전도.

본 논문은 농촌진흥청 차세대 바이오그린21사업(과제번호:PJ008068)과 2012년도 정부(교육과학기술부)의 재원으로 한국연구재단의 기초연구사업(과제번호:2012R1A1A2039968)의 지원을 받아 수행된 것임.

${ }^{1}$ 교신저자: (151-747) 서울시 관악구 관악로 1, 서울대학교 통계학과, 교수. E-mail: heeseok@stats.snu.ac.kr 